\title{
Article
}

\section{Librarians Attending Non-Librarian Conferences: Benefits and Preparing to Attend}

\author{
Amanda Nevius \\ Kathryn Houk, University of Nevada, Las Vegas \\ Erica Brody, Virginia Commonwealth University \\ Xan Goodman, University of Nevada, Las Vegas \\ Roy Brown, Virginia Commonwealth University \\ Christine Andresen, Medical University of South Carolina
}

\begin{abstract}
This experience-based opinion piece, authored by a diverse team of librarians, will empower readers to attend non-librarian conferences by acknowledging the benefits and challenges of doing so, along with advice for overcoming these challenges and making the most of this professional development and advocacy opportunity. A review of the literature provides background and support for Part 1, which discusses the benefits of attending non-librarian conferences, organized into the categories of broadening horizons, advocacy, and long-term benefits. In Part 2 we give advice for preparation for attending and overcoming challenges. We present Part 2 organized into the following themes: 1) Acquiring time, money, and support, 2) Defending against imposter syndrome, 3) Conference culture differences, and 4) Diversity, inclusion, and allyship. In our conclusion, we offer the opportunity for you to contact any member of the author team for mentorship or advice.
\end{abstract}

\section{KEYWORDS}

Professional development, conferences, advocacy

\section{SUGGESTED CITATION}

Nevius, A.; Houk, K.; Brody, E.; Goodman, X.; Brown, R.; \& Andresen, C. (2022). Librarians attending non-librarian conferences: Benefits and preparing to attend. Journal of New Librarianship, 7(1), 39-62. https://doi.org/10.33011/newlibs/11/5

This is an Open Access article distributed under the terms of the Creative Commons Attribution 4.0 International License (http://creativecommons.org/licenses/by/4.0), which permits unrestricted use, distribution, and reproduction in any medium, provided the original work is properly cited. 


\section{Introduction}

Librarians often focus on attending conferences designed for our profession, whether large, traditional ones like the annual meeting of the American Library Association or events offered by newer organizations such as The Library Collective. However, librarians may be unaware of non-librarian conferences, unsure of the benefits of participation, or hesitant of their ability to have a meaningful experience if they attend. In this paper we, a group of six librarians who have attended and presented at various disciplinary conferences, encourage you, our readers, to consider expanding your professional development beyond library conferences. Our diverse experiences demonstrate that non-library conferences provide new opportunities for learning, as well as for developing and expanding professional networks of both librarians and non-librarians. We find that these events offer many benefits, but also present both familiar and new challenges for attendance. In this paper, we will discuss the opportunities other librarians have found in librarian conference attendance, our own thoughts on the benefits of attendance, and our experiences with, and advice on overcoming, challenging situations.

\section{Literature Review}

The literature has a small collection of articles and book chapters published in the past two decades on the topic of librarians joining disciplinary professional organizations or attending their conferences; the majority of these are case reports, editorials, or essays describing benefits.

In a 2014 book, Revolutionizing the development of library and information professionals: Planning for the future, two chapters explore the idea of conference attendance as professional development for librarians (Hines, 2014). In her research, Hines explored the motivations of librarians for attending professional development events (2014b). Though not broadly generalizable, it appeared that librarians valued the information provided during conference sessions, the ability to network, renewed enthusiasm from an influx of new ideas and perspectives, and the ability to discover potential new additions to library collections (Hines, 2014b). Bradshaw undertook a combination of a literature review and content evaluation of the websites of major professional associations in librarianship in order to frame her argument that professional development should occur beyond library conferences alone (2014). Librarians are expected to provide support across ever-expanding areas of research and service, and library conferences cannot be expected to cover training and insights into all of these new areas (Bradshaw, 2014). Attendance at disciplinary or trade conferences outside of librarianship can help support librarians in emerging roles.

In her 2002 article, Tysick outlined several positive but intangible outcomes she experienced after attending two disciplinary conferences. Benefits ranged from collection development, personal skill-building, and increased library prestige and relevance on campus. Several other articles similarly detail the unique experiences and tangible and intangible 
benefits of attending disciplinary conferences, and the potential harms of never venturing beyond library conferences (Bradshaw, 2014; Cassner and Adams, 2012; Hankins, Melgoza, Seeger \& Wan, 2009; Harrison, 2010; Hood, 2007). Many of the case reports and opinion articles took a more limited scope in the purpose of disciplinary conference attendance. For example, Lyons' 2007 case report focused on the benefits and challenges of attending disciplinary conferences for collection development purposes. The only challenge discussed is that of the cost of attendance, and the rest of the paper focuses on the benefits to librarians and library collections (Lyons, 2007). A 2009 article by Tomaszewski and MacDonald focused on assisting academic librarians in finding and identifying appropriate disciplinary conferences to attend for professional development. In addition, a 2012 article by Kassner and Adams outlined professional development opportunities, including disciplinary conferences, specifically for distance learning librarians. These three articles provide very specific reasons for attending disciplinary conferences but discuss similar benefits to attendance discussed earlier.

In Identifying liaison opportunities through content analysis: Academic library trends in the Ecological Society of America's conference program, Conklin describes coding the proceedings of an ecology conference and discusses several potential areas of opportunity for liaisons that were uncovered from the trends and resources listed (Conklin, 2013). Many of the benefits described are similar to the articles describing physical attendance, including identifying new areas for supporting faculty and identifying emerging trends in the discipline (Conklin, 2013). In one of the few research studies done to evaluate the benefits of librarians attending disciplinary conferences, Bennet (2011) found that librarians who were members of discipline-specific professional organizations gained positive outcomes even in the absence of conference attendance while saving money and time (Bennet, 2011). Specific benefits of membership observed include the following: insight about scholarship in the discipline to support collection development decisions; access to subject specialists to comment on librarian initiatives; and support to enhance librarians' identities as subject matter experts (Bennet, 2011).

A recent article by Price, et al. explores librarian attendance from the frame of the embedded librarian model (2020). Instead of examining the professional development benefits to the librarian, the paper describes librarians acting as social media ambassadors, presenters, and exhibitors in a local health sciences conference (Price, 2020). This is a unique addition to the body of literature because it explores a librarian being a more active participant, and even expert resource, within the disciplinary conference. The authors concluded that they gained many similar benefits as described in the rest of the literature, but they also had an impact on how disciplinary attendees thought about search methodologies and critical appraisal, and the expertise and role of librarians beyond collection managers (Price, 2020).

The literature on attending non-library conferences, or participating in professional organizations beyond librarianship, appears to be in consensus that it is beneficial to participate 
in professional development activities beyond those meant for librarians alone. However, the literature lacks any guidance on how librarians might best prepare and situate themselves to get the most out of attending disciplinary conferences. Brief mentions of opportunities for serendipitous discussions with faculty and discovering new tools and trends appeared in the discussions of most literature presented in this review, but more comprehensive tips on pitfalls and opportunities are not discussed. This paper reinforces the many benefits of non-library conference attendance as described from the perspective of a diverse group of academic health sciences librarians and adds to the literature by providing descriptions of situations authors have encountered at various conferences and practical suggestions in how to prepare for or deal with them.

\section{Contextualizing Our Views}

As an article of personal experiences and advice based on attendance at a variety of disciplinary conferences, it is important to us that you, the reader, understand the context of our author team. All six authors currently work for health sciences related disciplines, such as nursing, public health, implementation science, and dentistry. However, we also come from a variety of educational backgrounds of expertise. Our non-librarian disciplines include: Anthropology, Biology, English, History, Instructional Design \& Technology, International Relations \& African Studies, Psychology, Public Health, and Sociology. This diversity of interests is reflected in our participation in disciplinary conferences, with Houk participating in the Pop Culture Association Conference and Goodman participating in a conference on threshold concepts, an educational topic. We feel our advice is applicable to other academic disciplinary conferences as well. We are all based out of the United States in the following states: Massachusetts, Nevada, South Carolina, and Virginia.

Our authorship team consists only of librarians and does not include any non-librarian library staff. While it does include one author who is an African American cis-woman and one author who is a white cis-man, we acknowledge that makes our overall team 83\% non-Hispanic white and $83 \%$ cis-women. This is a reflection of the overall whiteness and femaleness of librarianship, which, according to the ALA's most recent Diversity Counts data in 2012 is $88 \%$ non-Hispanic white and 83\% female among librarians. They did not collect for trans or nonbinary identities, rather collecting binary female/male data only (American Library Association, 2012). We are unable to find reliable statistics on other aspects of diversity among librarians as a whole. The Medical Library Association reports from a 2019 survey that $67 \%$ of their respondents were heterosexual, but did not report on percent cis (Pionke, 2020). Our author team similarly is $67 \%$ heterosexual, with two authors part of the LGBTQIA+ community. We have no trans or non-binary authors. Our team includes authors of varying abilities and disabilities, most of whom do not wish to disclose, with the exception of Nevius's food allergy. We support our author team's concerns about protecting themselves in a culture steeped in ableism and trust you will practice radical belief in accepting that what we tell you about our 
team's ability status is true. We did not request our members to disclose their religious affiliation, if any. Our perspective thus, while intersectional, is mostly that of non-Hispanic white and entirely cis allies.

Each member of our team found our way to non-librarian disciplinary conferences through different paths, yet a common thread was an invitation or mentorship. Another librarian suggested to Nevius to keep an open mind to the potential benefits of attending disciplinary conferences of disciplines to which she liaises. Thus, when a faculty member invited her to present a poster on a systematic review she was an author on, she was ready to accept the opportunity. Goodman taught several workshops on systematic reviews, which led to her being invited to present a similar workshop at a non-librarian conference. Andresen was also invited to present at a non-librarian conference. Brown was asked to attend the Magnet Conference to learn how the library could better support the nursing population. Brody was encouraged by her supervisor to attend American Dental Education Association (ADEA). Two of our authors sought out attending non-librarian conferences themselves. Houk did so due to a desire to promote the varied expertise and skills librarians can bring. Goodman has her own research interest in threshold concepts, an area connected to education that extends beyond librarianship, which led her to pursue conferences on this topic. As we have found many benefits from attending non-librarian conferences, attendance which, for the majority of us, fell into our laps, we wanted to be the mentoring voice encouraging others to seek these conferences out for themselves.

\section{Part 1: Benefits of Attending}

\section{Broadening Horizons}

It is our experience that non-librarian conferences are a unique opportunity to learn from non-librarian perspectives in an immersive environment. These meetings provide ample opportunities to ask the questions you may have about a discipline during sessions as well as informal conversations throughout the event-all of which together can inform you of ways to better support the research and teaching goals of your patrons. Goodman attended the 7th Biennial Threshold Concepts International Conference and was struck by the different discipline-specific approaches to threshold concepts. Engaging with non-librarians around the big idea of threshold concepts encouraged Goodman to continue with her pursuit of learning more about how to apply threshold concepts to her work. The opportunity to connect with scholars, academics, practitioners, and others who are not librarians but are engaged in work related to your discipline(s), can be eye-opening and result in improving your knowledge, skills, and services in and for the disciplines you support.

It is also possible to build relationships with other librarians at these conferences. Some conferences offer separate librarian-themed sessions or interest groups, making it easy to identify other like-minded librarians who are open to exchanging experiences and perspectives. 
This provides a unique opportunity to exchange best practices, build skills, and obtain insight into the discipline-specific librarian praxis at other institutions. You may even find inspiration to explore new ways to become involved in the curriculum of the discipline. After attending an EDUCAUSE Learning Initiative (ELI) Annual Meeting, Andresen was inspired to engage in curriculum revision projects at her university which ultimately led to a joint appointment in the college she supports, thus demonstrating how the ability to connect with other librarians in a subject specialty can open the door to new collaborative partnerships. We find there is significant potential for joint scholarship opportunities when librarians meet at non-librarian conferences, and those connections could result in research projects, presentations, or publications. In fact, Nevius and Brody met at an ADEA conference which resulted in this manuscript.

\section{Advocacy}

Advocacy is an important aspect of the many attributes needed for becoming a wellrounded leader (Caplan, 2013). We find attending a non-librarian conference can be a great opportunity to practice this skill. You can showcase the depth and breadth of librarianship to discipline-specific faculty and staff, and thus advocate for the library and information science profession.

Opportunities for posters and presentations at conferences can help faculty and researchers come to see past preconceived notions of what role librarians can have. Librarian perspectives, while relevant to the discipline, are also unique, which can sometimes give an edge to being accepted if a conference is seeking greater diversity of perspectives in presentations. Goodman presented a poster on the international workshops she conducted in Nigeria. Conference attendees remarked that her poster was unique among all of the posters at the conference. Houk hosted workshops two years in a row on research data management at the Society for In Vitro Biology conference. Nevius has presented on her dental education innovations at the ADEA annual meeting, and Goodman presented about her work with public health at the Nevada Public Health Association annual meeting. All of these presentations fit within the themes of the conferences, but many in attendance were surprised when they learned that the posters or presentations were being given by librarians and indicated that their perception of librarians improved through our participation.

We find that if attendees view our poster or presentation as engaging and our answering of questions as skillful, some of the attendees inevitably seek us out later to learn more. These conversations often expand into opportunities to highlight the expertise and services that academic librarians can provide. Most of us found ourselves advocating for the services we personally provide and recommending that the non-librarian conference attendees inquire at their own institutions' libraries for similar services. 
It is important to be mindful of the fact that your library may provide a service that is not available at other institutions, so offer that caveat when presenting to an audience of discipline-specific educators and researchers from outside of your organization. Andresen experienced this situation during a Nursing Research Conference while giving a presentation on the library's systematic review services at her institution. Naturally there were conference attendees not affiliated with the author's organization, and therefore many did not have access to this kind of library service. The author used this opportunity to advocate for the librarian's role in healthcare research and encouraged attendees to connect with their own libraries and find opportunities to collaborate.

We find that the mere act of attending and interacting with discipline-specific faculty and staff in their own academic spaces leads to greater visibility of librarians and may result in greater understanding and acceptance of librarians' integral role in the academy. Brody spoke with the faculty director of a program at the disciplinary conference they both attended and later that faculty director reached out to her to conduct a literature review. Similarly, after attending Goodman's presentation at the disciplinary conference, a faculty member reached out to her and asked her to present to students in a course. There is a possibility that a majority of the conversations during the conference will contain elements of education about the roles and skills of librarians, similar to a typical on-campus interaction. However, discipline-specific faculty and staff may be more receptive to this new information in the conference setting, where they are away from day-to-day responsibilities and focused on learning. We have obtained the interest and respect of discipline-focused educators and researchers by asking questions and sharing ideas based on our knowledge and skills. We feel that such interactions also help break down the stereotypes many hold about the profession. Nevius experienced this when a faculty member from a different institution approached her after a presentation on pedagogy, surprised that a librarian would be interested in pedagogical methods. This faculty member closed the conversation by stating that she intended to seek out her own institutional librarian after the conference due to her new understanding of the role librarians can have.

Tysick suggested in 2002 that librarian attendance at disciplinary conferences advocates for the library itself as a whole. Our experience both supports this and takes it one step further, indicating that, by advocating at disciplinary conferences for librarians and the services they provide, libraries as a whole could experience an increase in the usage of services and resources. Professionals from various disciplines interacting with librarians in this setting may begin to view librarians as credible and valuable members of their discipline, as well as potential collaborators for future projects, regardless of whether their institution's librarian attended the conference.

\section{Long-Term Benefits}

The potential benefits of attending disciplinary conferences are not limited to the time at the conference itself. We also find that attending these events has long-term positive impacts on 
our careers. A significant impact is the connections and collaborations authors make while attending these conferences that endure after the conference has ended. Brodyhighlights how attendance at ADEA led faculty at her own institution to treat her as an equal colleague upon their return to work. Goodman similarly notes that faculty at her institution began seeking her out to partner on research and serve on graduate level committees. Andresen was invited to join faculty research teams at her own institution, which then led to non-librarian conference presentations and publications with these teams. Houk notes her connections led to webinar presentations on conducting research for non-academy professionals in public health. She also invited non-librarian faculty to present with her at a librarian conference, which they accepted and later expressed their enjoyment of the opportunity. Brown also found that his connections to those at other institutions led to their inviting him to serve as a facilitator of educational opportunities outside of his employer. He also was invited to work on a grant to redesign and participate in teaching a course at his own institution. Nevius was similarly invited to present an educational session for faculty at another institution by a dean who attended her presentation on the same topic at a disciplinary conference. She also was nominated to a leadership role in a special interest group at the disciplinary conference she attended.

Many of us also indicate the long-lasting personal impact of information learned at these conferences. Houk notes that her attendance has expanded her own personal areas of professional interest. Both Brody and Brown highlight that their attendance led to a greater understanding of the big picture and the challenges faced by the disciplines they work with. Brody observes that seeing how others with different expertise teach helps give her new instruction ideas herself. Andresen states that she was brand-new to supporting the discipline whose conference she attended, and the attendance built her knowledge of the discipline.

These interdisciplinary connections are a two-way street of benefit and respect. Many of us indicate that we did not experience a similar level of recognition as a valued member of the team in the discipline until after our attendance at these conferences. It is one thing to tell a colleague you can assist them with a project. It's another thing for them to see your expertise in action. The latter leads to more meaningful invitations, as well as greater receptivity to our own invitations in return. In our experience, seeing us at their own disciplinary conference does more to make connections than voluminous amounts of seeing and hearing us at our own institutions. While Nevius does note that it should not be necessary to convince others of our value as team members, it is a reality many of us deal with, and this can be a solution.

Librarianship, like many professions, can sometimes become an echo chamber of ideas and methods. We find that attending conferences of other disciplines offers different perspectives and methods that can reinvigorate our own work in many ways. We might come to understand the disciplines we work with better, making the assistance, solutions, and teaching we offer more suited to them. We also might find exposure to ideas that are relevant to many disciplines and bring those ideas back to our own librarian committees and teams, helping to 
broaden ideas beyond those we are most familiar with in library circles. Now that we have established some potential benefits of attending non-librarian conferences based on our own diverse experiences, we will address aspects of preparing for the non-librarian conference.

\section{Part 2: Preparing to Attend and Overcoming Challenges}

While attendance at any conference regardless of type requires preparation, it can be relatively simple to find a colleague who has attended a librarian conference for advice on how to prepare. However, it might not be so simple to find a colleague who has attended a nonlibrarian conference. We address your potential need for this advice by using our experience to give guidance both on what types of preparation are similar or have the potential to be similar between librarian and non-librarian conferences and what types of preparation might have more unique needs for the non-librarian conference.

\section{Acquiring Time, Money, and Support}

Attendance at any type of conference typically requires a significant investment of time and money. Articles focused on professional development, within and outside of libraries, cite budgetary issues as a barrier to attending conferences and outside training opportunities (Blessinger \& Costello, 2011; Cassar, Whitfield \& Chapman, 2020; Kendrick, Leaver \& Tritt, 2013). If cost is a known issue for you, it may help to consider virtual rather than physical conferences, as these typically have a lower registration fee and no cost for travel. You could also consider a conference in close proximity to minimize travel costs. You may want to determine which, if any, meals are included with the cost of registration. We find that some conferences, particularly in certain subject areas, can actually have a fairly low registration fee. Andresen registered for a conference for just $\$ 60$, as compared to the American Library Association's fee of $\$ 320$ (Table 1). All of these options preemptively lower the cost of attendance and we advise investigating them first. Attendance at a non-librarian conference may require a bit more strategizing to obtain the administrative and financial support needed. We advise preparing a proposal to aid with this. 


\section{Table 1}

Conferences Attended by Authors by Subject Area with Registration Fees

Conference
Registration Fees

(Year)*
Author(s) in Attendance

\begin{tabular}{lll}
\hline \multicolumn{3}{c}{ Education } \\
\hline International Threshold Concepts Conference & $\$ 275(2018)$ & [Author 4] \\
Hawaii International Conference on Education & $\$ 315(2021)$ & [Author 2] \\
American Dental Education Association & $\$ 689(2020)$ & [Authors 1, 3]
\end{tabular}

\section{Health Sciences}

Lowcountry Nursing Research Conference

Nigeria Implementation Science Alliance

Nevada Public Health Association

American Nurses Credentialing Center National

Magnet Conference / Pathway to Excellence

Vizient/American Association of Colleges of Nursing

Nurse Residency Conference

Institute for Healthcare Improvement Conference

$\$ 60$ (2020)

$\$ 89.86$ (2020)

Conversion rate

from Naira to

dollars May 2020

$\$ 250$ (2020)

$\$ 750$ (2020)

$\$ 950$ (2019)

$\$ 1,250$ (2019)
[Author 6]

[Author 4]

[Author 4]

[Author 5]

[Author 5]

[Author 5]

\section{Sciences}

\begin{tabular}{lll}
\hline Society for In Vitro Biology & $\$ 200(2020)$ & [Author 2] \\
American Association for the Advancement of & $\$ 310(2020)$ & [Author 2]
\end{tabular}

Science

Technology

\begin{tabular}{lll}
\hline EDUCAUSE Learning Initiative & $\$ 579(2019)$ in & [Author 6] \\
& person / \$251 \\
& $(2020)$ online
\end{tabular}

Librarian Conferences for Reference/Context

American Library Association

Association of College \& Research Libraries

Medical Library Association
$\$ 320$ (2019)

$\$ 439$ (2021)

$\$ 709$ (2019)

${ }^{*}$ Calculated as non-student member rate.

The primary audience for a proposal to attend a conference is composed of library administrators who control professional development funds and decide whether work time may be used for conference attendance. You should also consider reaching out to partners outside of 
the library, such as faculty and administrators from the departments they support. They may have funding to contribute or provide a discounted registration rate through group membership in a professional organization. All stakeholders may be able to identify grant opportunities that could fund conference attendance. When Nevius first investigated attending ADEA, she reached out to the discipline she liaises with on behalf of the library and discovered she could become an ADEA member for free via the institutional membership. This helped mitigate the overall cost of the conference and gave her an additional free professional membership as well. Brown saw an even greater level of financial support through his deep connections in the hospital, through which he was able to obtain financial support to attend the national Magnet Conference for several years. Attending this conference enabled Brown to learn more about Magnet and identify more opportunities to support the work of the organization.

Financial support is not always immediately clear like in the situations delineated above. When Brown wanted to attend the Institute for Healthcare Improvement National Forum on Quality Improvement in Health Care and needed to seek out library administrative support for his attendance, he developed a communication plan to advocate for it. He reviewed the conference program online and identified key sessions he wanted to attend. He then tied these sessions directly to the performance improvement and evidence-based practice work he was doing with nurses in the hospital. He further showed the value of attending the forum by tying the sessions and conference objectives directly to the individual goals he had for the year. This provided his direct supervisor with clear points she was able to use to ensure he could attend.

We advise you to create a similar communication plan (Appendix A). It should include a timeline to ensure you submit proposals to stakeholders early enough so that those in the administration can consider the merits of the request and make plans accordingly. A reasonable timeline would be 6 - 12 months before needing to register for the conference. Every institution has different mechanisms in place that employees must navigate to gain support and funding, so the earlier you start the better. Ideally, formulate your communication plan at the beginning of the fiscal year for your institution. It is during this time that librarians must come up with goals for the coming year and budgets are put together. Being able to tie conference attendance to one's annual goals may help with financial resources being designated for attendance. This is particularly true when needing to secure financial and administrative support before submitting an abstract to a non-librarian conference.

We find that the most important part of the communication plan is the messaging. Explain the ways conference attendance will benefit you, your department, and your external partners. It is important to articulate your short- and long- term professional goals and document the learning opportunities provided by the conference to meet those objectives. This information can be obtained from reviewing the current or past conference agendas. 
The communication plan may also include networking opportunities that could result in establishing or deepening relationships with potential patrons and mentors. In addition, it should address any stakeholder concerns about conference attendance that can be anticipated. For example, library administrators may question how you will stay current with librarian praxis if attendance at a non-librarian conference keeps you from attending librarian-specific programs.

You should also describe how your use of institutional funds will benefit the organization. Potential organizational benefits include innovative practices for curriculum development, teaching, and research. We advise clearly communicating the ways you will share this new information with colleagues, such as via written reports, blog posts, or departmental presentations. In addition, you may wish to highlight how presenting at non-librarian conferences directly contributes to the stature of their organizations.

\section{Defending Against Imposter Syndrome}

Imposter syndrome is generally defined as feelings of doubt regarding your abilities or like an intellectual phony (Clance \& Imes, 1978; Tulshyan \& Burey, 2021). Literature documents that librarians particularly face imposter syndrome when engaging in work that requires fulfilling roles and enacting skills outside of their formal academic training (Singer Gordon, 2003; Barr-Walker et al., 2019). Currently, imposter syndrome is being critiqued and questioned, with many suggesting shifting the focus away from the individual experiencing these feelings and onto the racist, classist, misogynistic, bullying, traumatic systems that cause them (Andrews 2020; Tulshyan \& Burrey 2021). We support these critiques. Thus, when we say imposter syndrome, we mean it as a shorthand way of referring to these feelings of doubt and phoniness resulting from engaging in labor that places us in direct contact with flawed systems. Even if you have not previously experienced these feelings, it is possible, given the different settings and interactions of a non-librarian conference, that you might experience them.

When preparing for these potential feelings, we encourage you to start by reminding yourself that they are not a personal flaw but rather a symptom of an institutional problem (Andrews, 2020). Reframing these feelings as being about how professional communities are designed rather than focusing on yourself will help shift your perspective in a self-protective manner (Edwards, 2019). Beyond awareness of the systems that cause these feelings to arise, you can use tactics before and during the conference to help defend yourself.

Before the conference, you may research information to prepare yourself for a different cultural and disciplinary context. You may review the conference program to gain a broad understanding of the various themes to be discussed and identify sessions of interest at the conference. Also, prior research about discourse related to power dynamics in the field might be helpful (Andrews, 2020). The conference may have an app with the program that also provides a list of participants to help librarians identify attendees they would like to meet. Goodman used 
the Nevada Public Health Association conference app to learn about conference attendees and to participate in voting on conference posters.

You may review biographical information or material written by one or more keynote speakers presenting at the conference in preparation for discussions at and about these sessions. You can use social media to listen in on discipline-specific conversations that may continue at the conference. Librarians of color also suggest establishing a relationship with a mentor as a key tool in battling imposter syndrome (Lee \& Morfitt, 2020). This mentor could be another librarian who has attended a discipline-specific conference or an institutional colleague who has attended this conference in the past. In addition, research about the conference location may also help you to feel comfortable once at the meeting. For example, Goodman prepared to attend the Nigeria Implementation Science Alliance conference by reading about the local contexts for her workshops in two different Nigerian cities. All of this research can help build confidence and inform the types of questions you might ask to engage with others at the conference.

During the conference, it is our experience that these feelings are particularly likely to arise when we are questioned about our presence at a non-librarian conference. Many of us have been asked, "Why are you here?" The nuance of this questioning directed toward a librarian in a visible minoritized group, such as a non-white librarian, might have underpinnings in racism or other isms. For example, for Goodman who experienced this question and identifies as a Black person, this questioning might have been racial stereotyping. Why are you here might mean, why are you a non-white person who is not a member of this discipline at this conference? What are your credentials? What qualifies you to be in this environment? Touré (2011) describes this as resume checking for people of color. We suggest that Black, Indigenous, and People of Color (BIPOC) librarians as well as white allies prepare for the possibility of microaggressions by familiarizing themselves with the framework for BIPOC on deciding how to respond to microaggressions and suggestions for bystander allies provided by Washington, Birch, \& Roberts (2020).

If it does not feel to you that this type of questioning is a microaggression, it can be good to reconceptualize this surprise about your presence as an opportunity to share the various ways librarians support educators, researchers, clinicians, and students. We advise doing what Maryville University advises- prepare in advance by creating a list of things about yourself and your work you can brag about so you have that to fall back on as topics of conversation (2021). Our experience indicates that having a prepared response helps us better navigate the situation without lowering our moods. For example, our authors who attended the APHA and ADEA conferences took the question as an opportunity to converse with these attendees about the vital role libraries play in supporting scholarship, their enthusiasm and knowledge of the discipline, and discussing their own areas of research and service that contribute to the conference. This preparation thus prevented the potential negative feelings and shifted the moment into a positive interdisciplinary one. 
Ultimately, if you think you may be impacted by feelings typically associated with imposter syndrome, you can potentially help protect yourself against them by preparing in advance in these ways. For more in-depth reading and preparation on this particular challenge, please see Figure 1. In contrast, it is possible you will experience feelings quite the opposite of imposter syndrome at a non-librarian conference. It is possible you may feel more welcomed by the disciplinary conference than by a librarian conference and find that attendance helps you develop an increased sense of confidence. You might even discover new ways of contributing to the discipline and sharing your expertise via presentations at future meetings. Nevius was pleased by how welcomed she was at the first ADEA conference she attended, where members of her discipline's student group gave her a lanyard to represent her inclusion. While it is good to be prepared for negative feelings, it is also possible the disciplinary conference may be a positive and welcoming environment.

\section{Conference Culture Differences}

All conferences, whether librarian or non-librarian, have their own cultures, setting expectations around various behaviors such as dress code and session attendance. We advise not to make assumptions about what the culture of the conference may or may not be, but rather to investigate it in advance. One example is to reach out to colleagues who may have attended the conference of interest or similar and make inquiries about what to expect. There might be conference mentorship programs you could take advantage of, and more ways to prepare in advance are found in Figure 1. While it is important not to make assumptions, we offer observations from our own experiences of cultural differences, to provide some examples for clarification. 


\section{Figure 1}

Tips for Successful Conference-going

\section{STRANGERS IN A STRANGE LAND}

While attending a non-librarian conference, you may start to feel out of place in a new culture.

\section{AM I AN IMPOSTER?}

When attending a conference outside of your profession, you may experience a sense of imposter syndrome. Here are some recommended readings for overcoming those fears:

(?) What is Imposter Syndrome and How Can You Combat It?

https://tinyurl.com/y 7 my $98 \mathrm{n} 5$

Imposter Syndrome https://tinyurl.com/yad6oehc

The Empress Has No Clothes: Conquering Self-Doubt to Embrace Success

by Joyce M Roche with Alexander Kopelman

The Secret Thoughts of Successful Women by Valerie Young

\section{CULTURE CLASH?}

It can help to think of attending a conference for disciplinary educators as experiencing a new culture. Here are a few tips to help you successfully navigate and adjust:

Focus on your commonalities

Find tips from the conference or discipline for first-time attendees or students

Seek advice from a trusted colleague in the discipline 
Many librarian conferences, such as the annual meeting of the Medical Library Association, organize presentations into similar themes. There may be three different presentations in the same time-slot and room, but all share a common theme. Attendees are encouraged to go back and forth between different rooms to see the presentations they wish to see. Non-librarian conferences may organize presentations so that there is one presentation in one room during the entire time-slot, so it may be perceived as rude to arrive late or leave a presentation early. Even lightning talks may be organized in such a way that coming and going is bad form. Until you understand the conference culture, you should plan on staying for the duration of the sessions attended.

There is value in staying for the duration of sessions even if the conference culture allows for room swapping. It encourages mindful acceptance of the information that happens to come your way. Similarly, it helps you encounter information that may be unexpectedly relevant to your work. For example, Nevius attended an ADEA session and the first few minutes revealed that the content was about situations she was not likely to encounter as a librarian. However, the presenter used gamification via a tool called Kahoot!, which Nevius adopted to teach her own students.

Similarly, larger non-librarian conferences may schedule special interest groups to meet very early in the morning due to the fact that many involved may have other conflicting commitments. Sometimes events can go far into the evening or have few planned breaks throughout the day. It is important to be aware of these potential differences in advance and plan to manage your personal needs if there may be conflict with programming.

The "dress code" at conferences also varies. Most librarian conferences trend toward informal, including wearing comfortable clothing, addressing each other by our first names, and "black tie optional" official dinners. In contrast, the norm at ADEA is to address everyone formally with the title doctor, unless invited to do otherwise, and dress norms tend to run to professional attire. Attendees who identify as women attending ADEA are expected to wear nylons with dresses and heels. While we advise addressing others with the titles, names, and pronouns they expect, we also believe librarians can help pave the way toward these conferences being a more welcoming and diverse place by pushing back on expectations such as these.

As professionals who interact with a variety of disciplines, librarians are in a unique situation of being able to push the boundaries of conference culture slightly, because we are usually not subordinate to other attendees, such as those seeking employment or educational placement. When attending ADEA, Nevius considered that the largest issue in the unofficial dress code expectation was for women to wear high heels. Medicine acknowledges that this can be a health hazard (American College of Foot and Ankle Surgeons, 2020), and some in Human Resources consider mandatory wear to be a microaggression (Hammarling, 2017). While still wearing professional business attire, Nevius primarily eschewed high heels except for the most 
formal events. This led to positive dialogue with a faculty attendee from another institution about faculty taking the lead in changing this particular cultural expectation.

As these examples demonstrate, conference cultural differences can either be embraced mindfully or pushed against slightly and respectfully using your unique position as a nondisciplinary attendee. Both are growth opportunities for you as a professional.

\section{Diversity, Inclusion, and Allyship}

Diversity, inclusion, and allyship are essential considerations for all conferences, regardless of whether they are librarian or disciplinary focused. However, we want to draw attention to challenges and opportunities specifically at non-librarian conferences alongside advice on how to prepare to address or take advantage of them. Some of this advice can also apply to attendance at a librarian conference.

For BIPOC librarians, attending a non-librarian conference can be an opportunity to attend a conference designed as a supportive space for BIPOC in that discipline. Just as the Joint Council of Librarians of Color offers this space for librarians, non-librarian disciplines have created these spaces as well, such as People of the Global Majority in the Outdoors, Nature, and the Environment. For more examples, see Figure 2. If you choose to attend a conference that is not designed as a BIPOC space, it may be beneficial to do some research in advance as to the association's demographics, so you will be prepared for what you may encounter. While some disciplines, such as Social Work, have greater BIPOC diversity than librarianship (Data USA, 2018), others, such as Engineering, have a similar lack of BIPOC diversity paired with a small percent of cis women (National Science Foundation, 2019). It is important to be aware of these differences so you know in advance whether you may be joining a room or space with an array of diverse identities or one consisting of mostly white cis men. Beyond data regarding attendees, it can also be beneficial to look and see if the group sponsoring the conference has any special interest groups for underrepresented identities or a task force or group dedicated to diversity, equity, and inclusion.

The labor of checking for inclusivity should not fall only on our BIPOC librarian colleagues. Indeed, we call on white allies to also investigate this information in advance and, if it seems the conference is both not diverse and not committed to diversity, to consider if this is a conference it is worthwhile to support. Is there another with a better commitment to inclusion and diversity to support instead? If there is not another, are you committed to working proactively to help make this a better space?

Inclusivity of course is not only about race and ethnicity but also about many other factors including, but not limited to support for: different abilities, LGBTQIA+ attendees, attendees who are parents, and attendees with religious needs and preferences. It is important to consider all aspects of diversity and inclusion when considering a conference. There are many potential areas of inclusion to investigate, but here are a few to keep in mind. Are important 
conference events scheduled at times of the day or on days that exclude members of certain religious communities? Are provisions in place to ensure those with dietary restrictions, whether for allergies, sensitivities, or personal/cultural/religious reasons, are able to participate fully in any events planned surrounding food, such as award dinners? Are strategies in place to aid working parents or caregivers in finding childcare during the conference? Are lactation rooms available for breastfeeding attendees? Does the conference offer a way for attendees to display their pronouns, including non-binary identities? Is there a plan in place at the conference for attendees to report diversity and inclusion issues they might see? A code of conduct may be available either on the conference website or within association documentation. If you cannot find one, it is worth getting in touch with conference organizers and providing a suggestion through conference evaluation and feedback options that a code of conduct should be developed and shared in a publicly accessible manner to make conferences more inclusive. Reminding leaders of the importance of following through when the code has been violated is also critical for successful adoption and implementation. It is important to keep in mind that just because there is a diversity and inclusion statement from the conference does not necessarily mean all attendees will feel welcomed. If it is possible for you to reach out to someone who has attended the conference before to find out what their perception is of its inclusivity, that can be beneficial.

Regardless of advance preparation, it is possible once at the conference you will encounter a situation that could be improved. Consider where you might have advantages and how you can work to make the conference a more welcoming place for others. For example, a cis ally can request gender-neutral bathrooms at conferences. Attendees can use suggestion boxes or post-conference surveys to call out changes that would help the conference be a more welcoming place for all colleagues. An important first step is reminding yourself not to make assumptions about other attendees. If you are interested in more formal training on how to be a better bystander please look to the suggested resources in Figure 2. 


\section{Figure 2}

\section{BIPOC-Friendly Conferences}

\section{ALLYSHIP \& SAFE SPACES}

You may either find yourself in situations where you need to be an ally, or looking for conferences outside of librarianship that offer a safer experience for historically marginalized professionals.

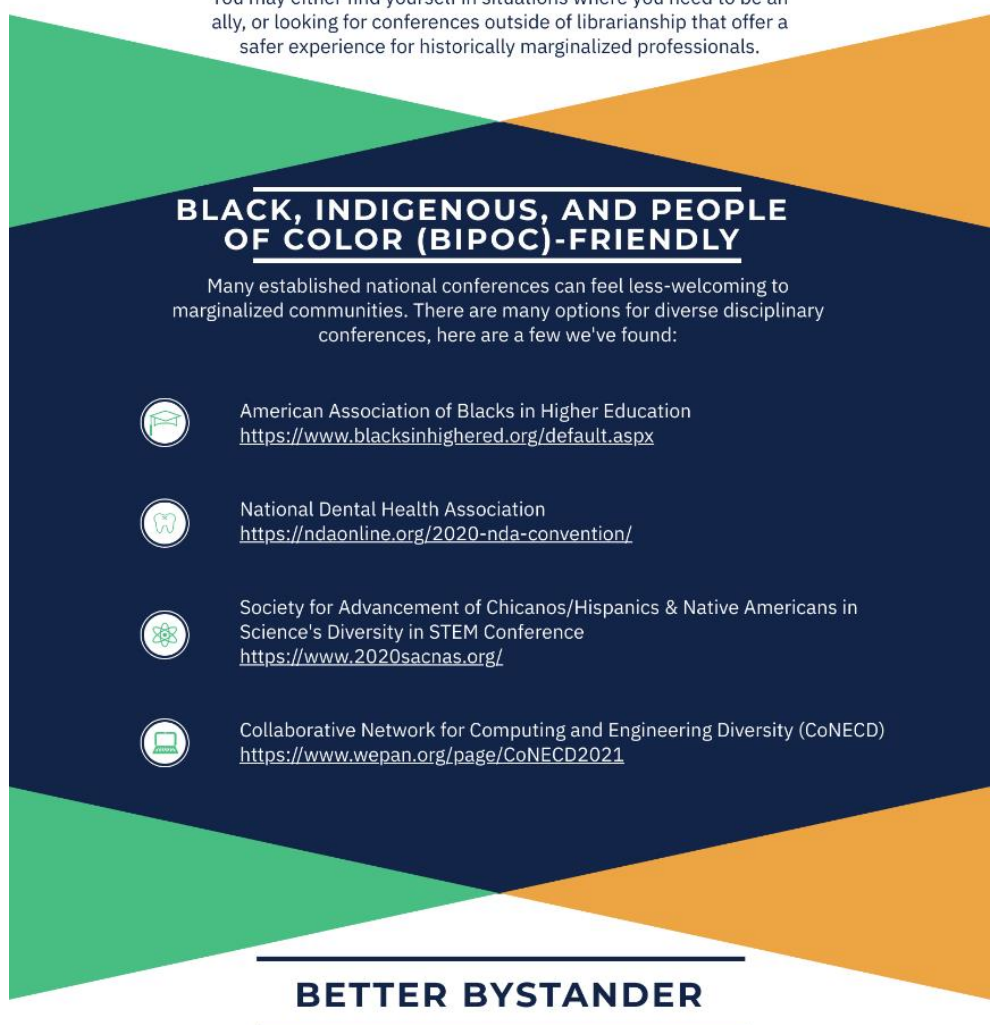

You may need to stand up for others while experiencing a new and different conference culture. Here are some resources to help you become a better ally and bystander.

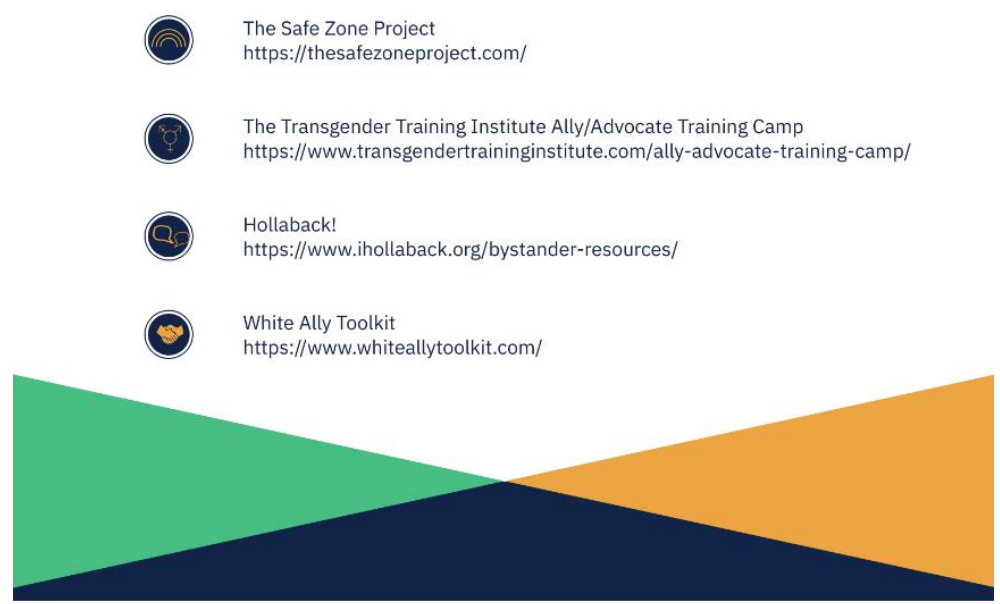


We find that our awareness of diversity, equity, and allyship issues have only increased by bringing greater variety into the types of conferences we have attended. Seeing for ourselves how different disciplines address these issues helps us liaise between these disciplines to better learn from each other. For example, Nevius can bring her experience from librarian conferences that manage food allergies well to provide specific, real-world advice to non-librarian conferences that are struggling to do so. Houk attended a conference that did not use platforms in some of the presentation rooms, a very common occurrence at national library meetings, and found it not only reduced physical barriers for those with mobility issues, but increased the intimacy of presentations and seemed to encourage more discussion between presenters and the audience. We hope through investigating the conference you are considering attending in advance and considering these examples we have provided you will feel more prepared to both address potential challenges and see potential benefits.

\section{Conclusion}

We find that non-librarian conferences give us as librarians the opportunity to broaden our horizons via the information we consume about other disciplines and the relationships we build. Perhaps more important, however, is the opportunity to build the important leadership skill of advocacy and promote the expertise and capabilities of librarians. This paper sought to inform you of the potential benefits of attending non-librarian conferences to empower you to have the most positive experience possible with advice from our own experience on how to best prepare. We hope our advice and your future attendance will help you become an advocacy leader, by increasing awareness of the services that librarians can provide and make a positive impact on the culture and diversity and inclusion efforts at these conferences over time. If you are looking for advice or a mentor in taking on this challenge, we encourage you to reach out to any of the authors. See Table 1 to see which author has an interest in which subject area. 


\section{References}

American College of Foot and Ankle Surgeons. (2020). Foot health facts for women - Foot health facts. Retrieved April 28, 2020, from Foot Health Facts website: https://www.foothealthfacts.org/article/foot-health-facts-for-women

American Library Association. (2012). Diversity counts [Text]. Retrieved November 19, 2020, from About ALA website: http://www.ala.org/aboutala/offices/diversity/diversitycounts/divcounts

Anderson, L. V. (2016, April 12). Feeling like an impostor is not a syndrome. Slate Magazine. https://slate.com/business/2016/04/is-impostor-syndrome-real-and-does-it-affectwomen-more-than-men.html

Andrews, N. (2020, June 10). It's not imposter syndrome: Resisting self-doubt as normal for library workers. In the Library with the Lead Pipe. http://www.inthelibrarywiththeleadpipe.org/2020/its-not-imposter-syndrome/

Barr-Walker, J., Bass, M.B., Werner, D.A., \& Kellermeyer, L. (2019). Measuring imposter phenomenon among health sciences librarians. Journal of the Medical Library Association, 107(3). 323-332. https://dx.doi.org/10.5195/jmla.2019.644

Bennett, M. H. (2011). The benefits of non-library professional organization membership for liaison librarians. The Journal of Academic Librarianship, 37(1), 46-53. https://doi.org/10.1016/j.acalib.2010.10.006

Blessinger, K.D. \& Costello, G. (2011). The effect of economic recession on institutional support for tenure-track librarians in ARL institutions. Faculty Publications, 43. https://digitalcommons.lsu.edu/libraries_pubs/43

Bradshaw, A. K. (2014). Contrasting professional development and continuing education opportunities for library professionals: Offerings both within and outside the profession. In S. Hines (Ed.), Revolutionizing the development of library and information professionals: Planning for the future (pp. 1909-1927). IGI Global.

Caplan, A. (2013, May 2). Leadership and advocacy. Retrieved May 18, 2020, from Public Libraries Online website: http://publiclibrariesonline.org/2013/o5/leadership-andadvocacy/

Cassar, J., Whitfield J. \& Chapman A. (2020) Contemporary factors influencing association conference attendance. Journal of Convention \& Event Tourism, 21(1), 57-90. https://doi.org/10.1080/15470148.2020.1719948 
Cassner, M. \& Adams, K. E. (2012). Continuing education for distance librarians. Journal of Library \& Information Services in Distance Learning, 6(2), 117-128. https://doi.org/10.1080/1533290X.2012.694338

Clance, P. R., \& Imes, S. A. (1978). The imposter phenomenon in high achieving women: Dynamics and therapeutic intervention. Psychotherapy: Theory, Research \& Practice, 15(3), 241-247. https://doi.org/10.1037/hoo86006

Conklin, J. L. (2013). Identifying liaison opportunities through content analysis: Academic library trends in the Ecological Society of America's conference program. Issues in Science \& Technology Librarianship, 73(7). https://doi.org/10.5062/F4VXoDGD

Data USA. (2018). Social workers | Data USA. Retrieved November 19, 2020, from https://datausa.io/profile/soc/social-workers\#demographics

Edwards, C. W. (2019). Overcoming imposter syndrome and stereotype threat: Reconceptualizing the definition of a scholar. Taboo: The Journal of Culture and Education, 18(1), 18-34. https://doi.org/10.31390/taboo.18.1.03

Hammarling, N. (2017, June 21). Stamping out sexism: why kicking high heels off office dress codes is still important [Text]. Retrieved April 28, 2020, from HRZone website: https://www.hrzone.com/lead/culture/stamping-out-sexism-why-kicking-high-heelsoff-office-dress-codes-is-still-important

Hankins, R., Melgoza, P., Seeger, C., \& Wan, G. (2009). Meeting our users where they conference: A Texas A\&M model to support librarian attendance at subject-specific conferences. Public Services Quarterly, 5(2), 98-113. https://doi.org/10.1080/15228950902837541

Harrison, R. (2010). Unique benefits of conference attendance as a method of professional development for LIS professionals. The Serials Librarian, 59(3-4), 263-270. https://doi.org/10.1080/0361526X.2010.489353

Hines, S. (Ed.). (2014a). Revolutionizing the development of library and information professionals: Planning for the future. IGI Global.

Hines, S.S. (2014b). What do library workers want from professional conferences? In S. Hines (Ed.), Revolutionizing the development of library and information professionals: Planning for the future (pp. 1-16). IGI Global. 
Hood, I. (2007). Why we really need to argue for "getting about a bit.”. (cover story). One Person Library, 24(4), 1-3.

Kendrick, K.T., Leaver, E., \& Tritt, D. (2013). Link up the sticks: Access and barriers to professional development for small and rural academic librarians. Codex: The Journal of the Louisiana Chapter of the ACRL, 2(3), 38-77. https://scholarcommons.sc.edu/aiken_gregg_graniteville_library_facpub/4/

Lee, E., \& Morfitt, P. (2020). Imposter syndrome, women in technical services, and minority librarians: The Shared Experience of Two Librarians of Color. Technical Services Quarterly, 37(2), 136-147. https://doi.org/10.1080/07317131.2020.1728125

Lyons, L. E. (2007). The dilemma for academic librarians with collection development responsibilities: A comparison of the value of attending library conferences versus academic conferences. The Journal of Academic Librarianship, 33(2), 180-189. https://doi.org/10.1016/j.acalib.2006.12.001

Maryville University. (2021, February 2). Exploring impostor syndrome from a black perspective. Maryville Online. https://online.maryville.edu/blog/impostor-syndromeblack-perspective/

McMillon-Dantley, C. (2020, October 29). The imposter syndrome and its impact on black Women. BlackDoctor.Org. https://blackdoctor.org/the-imposter-syndrome-and-itsimpact-on-black-women/

National Science Foundation. (2019, March 8). Women, minorities, and persons with disabilities in science and engineering: 2019. Retrieved November 19, 2020, from National Center for Science and Engineering Statistics website: https://ncses.nsf.gov/pubs/nsf19304/data

Pionke, J. J. (2020). Medical Library Association Diversity and Inclusion Task Force 2019 survey report. Journal of the Medical Library Association: JMLA, 108(3), 503-512. https://doi.org/10.5195/jmla.2020.948

Price, C., Kudchadkar, S. R., Basyal, P. S., Nelliot, A., Smith, M., Friedman, M., \& Needham, D.M. (2020). Librarian integration into health care conferences: A case report. Journal of the Medical Library Association : JMLA, 108(2), 278-285. https://doi.org/10.5195/jmla.2020.803 
Singer Gordon, R. (2003). Overcoming the systems librarian imposter syndrome. LIBRES 13(2), 1-4.

Tomaszewski, R., \& MacDonald, K. I. (2009). Identifying subject-specific conferences as professional development opportunities for the academic librarian. Journal of Academic Librarianship, 35(6), 583-590. https://doi.org/10.1016/j.acalib.2009.08.006

Touré. (2011). Who’s Afraid of Post-Blackness?: What It Means to Be Black Now Free Press.

Tulshyan, R., \& Burey, J.-A. (2021, February 11). Stop telling women they have imposter syndrome. Harvard Business Review. https://hbr.org/2021/02/stop-tellingwomenthey-have-imposter-syndrome

Tysick, C. (2002). Attending conferences outside of librarianship. College \& Undergraduate Libraries, 9(2), 75-81. https://doi.org/10.1300/J106vo9no2_o8

Washington, E. F., Birch, A. H., \& Roberts, L. M. (2020, July 3). When and how to respond to microaggressions. Harvard Business Review. https://hbr.org/2020/o7/when-and-howto-respond-to-microaggressions 